\title{
Fotografía y representación en la novela El mapa y el territorio de Michel Houellebecq
}

Diseñadora Gráfica con más de 10 años de experiencia tanto en el ámbito institucional como en el ejercicio independiente de la profesión. Mi ámbito de trabajo son la comunicación corporativa, marketing institucional y editorial. Me interesan la comunicación
visual, fotografía, cultura visual, diseño de información visual, fotografia, cultura visual, diseño de información yurse gactín diCom, en la Facultad de Arquitectura, Diseño Urbanismo de la Universidad de Buenos Aires. (D) http://orcid.org/0000-0001-6638-3639.

E-mail: mcbaranlloni@gmail.com.

\section{Recebido em: 4/5/2019}

Publicado em: 16/12/2019

\section{Endereço:}

1108, Valparaiso, Región de Valparaiso, Chile.

\section{Photography and representation in the novel The map and the territory by Michel Houellebeca Fotografia e representação no romance O mapa e o territorio, de Michel Houellebeca}

Maria Cristina Baranlloni Lagos ${ }^{1}$

Universidad de Valparaíso, Escuela de Deseño, Valparaíso, Chile.

\section{RESUMEN}

Esta investigación tiene por objetivo acercarse a diversas problemáticas sobre fotografía y representación que surgen en la novela El mapa y el territorio del escritor francés Michel Houellebecq. El análisis circulará por cuatro ejes: el primero examinará la relación entre los distintos tipos de representaciones visuales que comparecen en dicho texto, luego analizaremos las miradas fotográficas existentes en la novela, continuaremos entendiendo el interés hacia los mapas del protagonista como una suerte de punctum y finalizaremos ahondando la relación entre la muerte de un ser querido con el mapa y la fotografía.

PALABRAS CLAVES: mapa; fotografía; representación; literatura; territorio.

\section{ABSTRACT}

The purpose of this research is to approach various subject matter about photography and representation that arise in the novel The Map and the Territory by the french writer Michel Houellebecq. The analysis will circulate through four axes: the first will examine the relationship between the different types of visual representations that appear in that text, then analyze the existing photographic views in the novel, we will continue to understand the interest in the protagonist's maps as a kind of punctum and we will end by deepening the relationship between the death of a loved one with the map and the photograph.

KEYWORDS: map; photography; representation; literature; territory.

\section{RESUMO}

A presente pesquisa procura analisar diversas temáticas relativas à inter-relação entre fotografia e representação expressas no romance $O$ mapa e o território, do escritor francês Michel Houellebecq. A análise possui quatro eixos de investigação: o primeiro examinará a relação entre os diferentes tipos de representações visuais que se reverberam no texto. Na sequência, analisam-se as fotografias presentes no romance no intuito de compreender o interesse dos mapas do protagonista como um tipo de punctum. Por fim, aprofundamos as conexões entre a morte de um ente querido com o mapa e a fotografia. PALAVRAS CHAVES: mapa; fotografia; representação; literatura; território. 


\section{Acerca de la novela a analizar.}

T a novela "El mapa y el territorio" fue publicada en el año 2010 por el poeta, ensayista y novelista francés Michel Houellebecq. La trama gira alrededor de la vida personal y carrera artística de Jed Martin, fotógrafo y artista francés al que seguirá desde el inicio de su obra hasta su muerte a avanzada edad.

El título de la novela surge del nombre de la exhibición fotográfica que consagrará artísticamente a Martin, titulada "El Mapa es más interesante que el territorio" y que consistirá en una serie de treinta ampliaciones fotográficas - estética y compositivamente muy bien cuidadas - realizadas a partir de los Mapas Michelin ${ }^{2}$ correspondientes a distintos departamentos (cantones) rurales franceses.

\section{El mapa, el territorio y la fotografía: como (re)presentar y (re)producir el mundo}

Existe en el título de la exhibición de Martin una clara puesta en diálogo con lo planteado por Alfred Korzybski (1994) para quien:

un mapa no es el territorio que representa, pero, si es correcto, tiene una estructura similar a la del territorio, lo que explica su utilidad (...) Si reflexionamos acerca de nuestros lenguajes, encontramos que, en el mejor de los casos, deben ser considerados tan sólo como mapas. Una palabra no es el objeto que representa (KORZYBSKI, 1994, p. 58; traducción y subrayados propios, cursivas en el original). ${ }^{3}$

Los Mapas y Guías Turísticas Michelin fueron creados en 1900, lo que los convierte en los más antiguos y de mayor tradición de Europa. En ellos se entrega información sobre conectividad vial (mapas carreteros) y además indicaciones turísticas, dado que se ofrecen evaluaciones de hoteles y restaurantes. Más información en http://www.michelin.es/servicios/mapas-y-guias.

En el original: "a map is not the territory it represents,but, if correct, it has a similar structure to the territory, wich accounts for its uselfulness (...) If we reflect upon our languajes, we find at best they must be considered only as maps. A word is not the object it represents." (KORZYBSKI, 1994, p. 58. traducción y subrayados propios, cursivas en el original).
Debemos entonces entender que la imagen propia que poseemos de la realidad no es nada más que una versión - una suerte de mapa a distinta escala - de lo existente. Precisamente transita por toda la novela la idea de como el "mundo real" es atravesado por las diversas representaciones que de él realizan los hombres, representaciones entre las cuales está la fotográfica y la cartográfica. Es la nueva visibilidad contemporánea donde se hace difícil determinar los parámetros de lo real, dado que hemos constituido una mirada mediatizada por la tecnología.

Por otro lado, hay en este tomar fotografías de un mapa una clara práctica de simulacro, entendida como una copia idéntica de un original que no existe, donde: "el territorio ya no precede al mapa ni le sobrevive. En adelante será el mapa el que preceda al territorio - PRECESIÓN DE LOS SIMULACROS - y el que lo engendre". (BAUDRILLARD, 1978, p. 5-6, mayúsculas en el original).

Es en esa construcción de lo real - la que incluso puede desbordarse y perder todo tipo de lógica objetiva y operativa - desde donde surge por ejemplo el mapa escala 1:1 del relato "Del rigor de la ciencia" de Jorge Luis Borges (1946):

En aquel Imperio, el arte de la cartografía logró tal perfección que el mapa de una sola provincia ocupaba toda una ciudad, y el mapa del Imperio, toda una provincia. Con el tiempo, estos mapas desmesurados no satisficieron y los colegios de cartógrafos levantaron un mapa de Imperio, que tenía el tamaño del Imperio y coincidía puntualmente con él. Menos adictas al estudio de la cartografía, las generaciones siguientes entendieron que ese dilatado mapa era inútil y no sin impiedad lo entregaron a las inclemencias del sol y los inviernos. En los desiertos de oeste perduran despedazadas ruinas del mapa, habitadas por animales y por mendigos; en todo el país no hay otra reliquia de las disciplinas geográficas (BORGES, 1974, p. 847).

Este exceso planteado por Borges nos sitúa claramente frente a la intención - por momentos exagerada - tanto de aprehender como de modificar artificial y simbólicamente nuestro entorno; la naturaleza ha muerto como referente denotado real e ideal; ha sido anulada por la idea de territorio y su connotación como signo, construcción conceptual que a su vez será mediatizada gracias al mapa, que lo representa. 
Es la doble vida de la ciudad propuesta por Rama (1998); para quien coexisten en ella una ciudad real, conformada por su existencia material y una ciudad letrada, cuyo orden es el simbólico. Es precisamente esta última la que permitirá el triunfo de la urbe sobre el territorio, porque antes de ser llevada a cabo ésta debía aparecer en una representación simbólica que solo podían asegurar los signos, tanto las palabras que traducían la voluntad de esa edificación ideal como los planos que permitirían construirla, constituyéndose así el plano en un modelo cultural operativo al llevar incrustado un marco ideológico propio, muy lejos de ser un registro neutro.

Si Jed Martin nombra su exhibición fotográfica "El mapa es más interesante que el territorio", claramente coloca en un lugar de superioridad jerárquica la representación por sobre lo representado. Pero además no debemos olvidar que su obra es una fotografía del mapa, es decir es una nueva representación, a la que además nuevamente pone por sobre lo "real", estatuto esta vez anclado en el mapa.

Será precisamente en los modos posibles de versionar lo real - de representarlo - donde la novela de Houellebecq pondrá un fuerte énfasis. Dicha situación será muy clara en el cartel de acceso a la exhibición fotográfica de Martin en donde aparecerán - una al lado de la otra - dos imágenes: una toma satelital de las inmediaciones de una localidad francesa y una de sus ampliaciones fotográficas del mapa Michelin de esa misma zona, en donde para él:

la foto satélite sólo mostraba una sopa de verdes más o menos uniformes sembrados de vagas manchas azules, mientras que el mapa desarrollaba una rejilla fascinante de carreteras departamentales, pintorescas, de vistas panorámicas, bosques, lagos y puertos de montaña (HOUELLEBECQ, 2011, p. 72, cursivas en el original).

De la preferencia de Jed Martin del mapa por sobre la imagen satelital resultará nuevamente una suerte de declaración de principios. Frente a una representación fotográfica del entorno que define caótica como "una sopa" - pero que en tanto indicial respondería por contigüidad a su referente, la localidad fotografiada - Martin preferirá el mapa. Éste emerge como una construcción conceptual y simbólica, altamente mediada por la cultura, donde se representa de manera detallada y ordenada el dominio humano sobre el territorio, exponiendo tanto las divisiones administrativas y políticas de la nación como su red de carreteras. Frente a estas dos posibilidades de representar el territorio Jed Martin optará por privilegiar el mapa, el que volverá a presentar - es decir a (re)presentar - esta vez fotográficamente.

Las imágenes a continuación ejemplifican el diálogo entre las imágenes presentes en el cartel de acceso de la muestra de Martin:

\section{Figura 1 - Vista satelital de Roma}

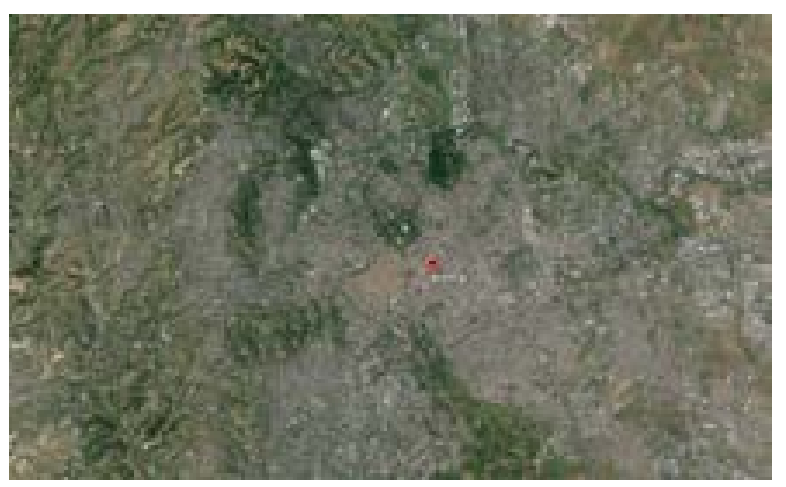

Fuente: Google Earth

Figura 2 - Fotografía de un mapa Michelin de la misma ciudad

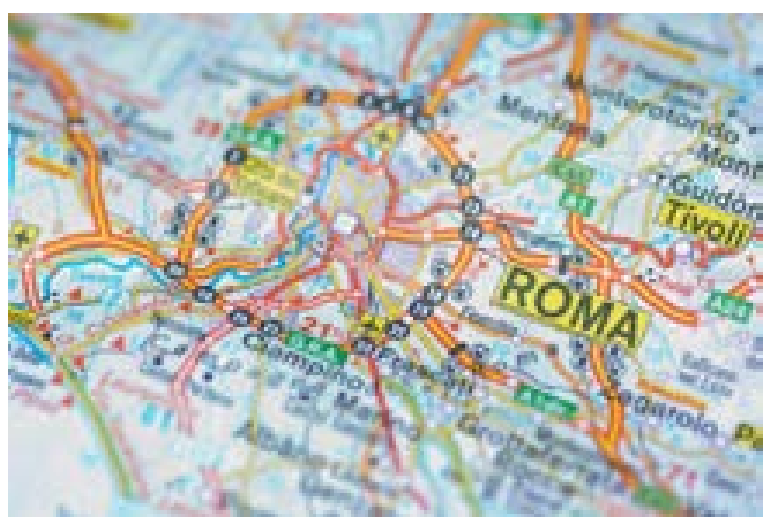

Fuente: Autor byggarn79 - https://pt.depositphotos.com/6386165/stock-photo-rome-map.html) 
Podemos además leer en esta suerte de descalificación hacia la fotografía satelital, una crítica implícita hacia los registros propios de la experiencia del no lugar (Auge: 2000); dada esa percepción de achicamiento del planeta a la que fuertemente han contribuido las nuevas tecnologías visuales que permiten el registro geo-referenciado en tiempo real; en los que subyacen doctrinas de control y vigilancia al constituir una mirada extraterrenal, mediada por la técnica y omnipresente que controla desde lo alto.

Frente a los esfuerzos objetivos de documentación planetaria propios del actuar de las fotografías satelitales, Jed Martin preferirá otro registro; que aunque también mediado por la técnica - en este caso la cartográfica - no conlleva la idea de control en tiempo real que posee la imagen satelital. Al privilegiar el mapa Michelin se producirá una clara reivindicación hacia un objeto caído en desuso frente a la "actual tiranía" de la imagen geo-referenciada; de hecho en la novela gracias a la obra de Martin el mapa Michelin presentó un importante repunte en las ventas, transformándose de un simple objeto utilitario a un "vehículo privilegiado de iniciación a (...) la magia del terruño.” (HOUELLEBECQ, 2011, p. 78).

\section{Registrar el mundo: \\ mirarlo desde lejos y mirarlo desde cerca}

Como revisamos anteriormente el paso desde la idea de naturaleza hacia la de territorio, es una reformulación funcional e implica a un hombre separado de su ambiente y que se le enfrenta en la tarea de controlarlo en el dominio de los signos y redes de mensajes.

Parte de ese control está claramente presente en la obsesión de Martin por registrar fotográficamente los objetos manufacturados por el hombre. Si bien la obra que le dará reconocimiento es "El Mapa es más interesante que el territorio", donde literalmente ponía el mundo bajo la lente de la cámara; ya desde sus inicios como estudiante en la Academia de Bellas Artes tuvo un interés por el mundo técnico propio del hombre, buscando registrar - o prácticamente inventariar dicho entorno artificial con una ambición enciclopedista; es ese claro empeño de la fotografía de "darnos la impresión de que podemos contener el mundo entero en la cabeza, como un antología de imágenes."(SONTAG, 2006, p. 15).
Precisamente, para ingresar a la Academia, Martin preparará una serie de trescientas fotografías de herramientas, donde "presentaba así tuercas, pernos y llaves inglesas como si fuesen joyas de un resplandor discreto" (HOUELLEBECQ 2011, p. 44), pero además dicho registro era realizado colocando las herramientas contra un fondo gris neutro, es decir alejándolas de su entorno cotidiano, desnaturalizándolas. Existe entonces entre ambas preocupaciones temáticas los objetos manufacturados y el Mapa Michelin - una clara vocación de registro y homenaje al trabajo humano, pero paradojalmente sin la presencia explícita de éste, sino que evocándolo a partir de su producción objetual ${ }^{4}$.

Esta ausencia del hombre en la obra de Martin genera un nexo con lo propuesto por Benjamin (1989) en relación a Eugène Atget; quien dejará de lado las grandes vistas características de París para detenerse en los detalles, realizando un proceso de extrañamiento entre el hombre y su entorno. Además, para Benjamin (2003) al eliminar al hombre de la fotografía, ésta perderá el valor de culto, su magia asociada a lo ritual; aumentando así su valor de exhibición, convirtiéndose en esa ciudad deshabitada que Atget fotografía como si fuese el escenario de un crimen, en busca de indicios. Si bien "para la fotografía, la renuncia al hombre es la más irrealizable de todas" (BENJAMIN, 1989, p. 76), lograrla será posible solo para aquel fotógrafo capaz de aprehender el medio ambiente y el paisaje como espacios vitales capaces de manifestarse en la placa fotográfica; siendo precisamente ese reconocimiento de lo vivo, incluso en situaciones que parecen carentes de él como la red de carreteras del mapa o las herramientas usadas a diario, lo que consiga la obra de Jed Martin.

Por otro lado Houellebecq presenta el quehacer fotográfico del protagonista con un acercamiento muy riguroso, describiendo de manera muy específica la relación corporal entre el fotógrafo y lo fotografiado. Cuando Martin se encontraba realizando algunas tomas del mapa Michelin nos detalla que él: "había utilizado un eje de toma muy inclinado, a treinta grados de la horizontal y regulado la basculación al máximo para obtener una gran profundidad de campo (HOUELLEBECQ, 2011, p. 56-57).

Nos parece que existe en este tipo de descripciones - abundantes en el libro - un escenario similar al planteado por Benjamin (2003) cuando compara al

Es relevante también acotar que el primer trabajo profesional de Martin será para dos agencias fotográficas especializadas en objetos y comida. 
camarógrafo de cine (figura que extenderemos en este caso al fotógrafo) con un cirujano, dado que el "operador de la cámara (...) penetra profundamente en el tejido mismo del hecho de estar dado" (BENJAMIN, 2003, p. 80) a diferencia del pintor - al que compara con el curandero - cuyo quehacer pictórico lo hace mantener una distancia natural con su referente.

En donde si existirá una evidente diferencia será en los modos de mirar ${ }^{5}$ propios de cada proyecto artístico. Al igual que en los mapas, hay en las obras de Martin dos escalas; en el caso de las fotografías de herramientas existe una cercana al tamaño real, propia del acercamiento hacia un objeto individual; y por otro lado en la fotografía de los mapas Michelin surge la escala mayor, propia de la cartografía y que promete la completitud de la mirada, el control de la totalidad y la escala global, es la cámara fotográfica que ha pasado a sustituir “el ojo de Dios"(BERGER, 1998, 73).

Existe entonces una clara confrontación entre dos maneras distintas de mirar: una desde la tierra, en contraposición a otra desde el aire; persistiendo en ambas la clara búsqueda del poder de la mirada fotográfica, la que puede ser reductiva, para apreciar lo inmenso, o por el contrario ampliada develándonos lo pequeño; pero en cualquiera de los dos casos, posibilidades lejanas a nuestra visión humana.

Para finalizar este apartado nos interesa señalar los interesantes guiños a la problemática de la reproducción presentes en la novela. Si como plantea Benjamin (2003) la reproducción separa a lo reproducido de la tradición, transformando a lo único en masivo; ¿qué sucede cuando lo fotografiado, el mapa, ya es una reproducción?, estamos así en frente a la reproducción de una reproducción. Surge de este modo la paradoja: los mapas Michelin son impresos en gran tiraje, son de alcance masivo; pero al ser fotografiados por Martin, dicha reproducción fotográfica los hará ingresar al circuito del arte por lo que volverán a ser vendidos en cantidades limitadas y a muy alto precio, aparecen así las dinámicas del mercado del arte, las que Martin debía aprender para lograr conocer "su precio en el mercado" (HOUELLEBECQ, 2011, p. 82).

En este sentido se hace necesario precisar la diferencia que hace Català entre el ver, entendido como un acto pasivo; al que se opone "la soberbia construcción humana que supone la mirada" (CATALÀ, 2001), es decir el mirar se constituye en una acción.

\section{El mapa como punctum}

Para Barthes (2008) coexisten en toda fotografía los conceptos de studium y punctum, los que logran producir un engranaje entre el contenido y la forma fotográfica; estableciendo diferentes niveles de implicación personal con la fotografía. El studium asociará los aspectos realistas y referenciales a la cultura, como el gusto y el significado universal de una fotografía, para los que todo espectador está de alguna manera entrenado; y por otro lado el nunca codificado punctum (pinchazo), emergerá como un detalle con gran fuerza de expansión y que apelará a las instancias fotográficas de carácter fuertemente personal.

Si bien Barthes propone ambos conceptos como propios de la fotografía, hay en el embelesamiento de Martin cuando se encuentra por primera vez con el mapa Michelin, un momento que claramente se puede asociar con el punctum:

nunca había contemplado un objeto tan magnífico, tan rico de emociones y de sentido, como aquel mapa Michelin a escala 1/150.000 de la Creuse, Haute-Vienne. En él se mezclaban la esencia de la modernidad, de la percepción científica y técnica del mundo, con la esencia de la vida anima (...) en cada una de sus aldeas, de los pueblos representados (...) se sentía la palpitación, el llamamiento de decenas de vidas humanas, de decenas o centenares de almas, unas destinadas a la condenación, otras a la vida eterna (HOUELLEBECQ, 2011, p. 47).

Frente al mapa definido por la $\operatorname{RAE}^{6}$ como "representación geográfica de la tierra o parte de ella en una superficie plana", es decir a ese acercamiento culturalmente codificado, propio del studium; Martin propondrá una fascinación tal por este objeto que le hará dedicar años a dicho proyecto fotográfico. Observamos que ambos conceptos también puedan ser utilizados para otros tipos de representación visual, no solo la fotográfica.

Precisamente colocamos la definición de la RAE; porque nos parece muy pertinente el anclaje que hace esta institución hacia la esencia del studium, que es la de ser referenciado por la cultura. 


\section{La muerte de un ser querido en el mapa y en la fotografía}

Antes de realizar la muestra "El mapa es más interesante que el territorio" Martin participó en una muestra colectiva en donde desarrolló su primera obra relativa a las guías Michelin; ésta será precisamente una fotografía del mapa del departamento de La Creuse donde vivió toda su vida su abuela paterna recientemente fallecida. A continuación, será precisamente esta relación, entre la muerte de un ser amado y la fotografía, a la que nos abocaremos.

Para Barthes (2008) en las fotos de quienes nos precedieron logramos reconocer una dimensión histórica; la que se constituye precisamente porque logramos mirarla - es decir estamos fuera de ella - dado que nos es ajena por el simple hecho de estar vivos. En dichas fotografías generalmente reconocemos a nuestros fallecidos de manera diferencial, encontramos en ellas partes de la persona - jamás una esencia completa - siendo escasas las imágenes donde éstas se nos muestren como una totalidad. Si Barthes descubrirá a su madre en la fotografía del invernadero; Martin hará lo propio con su abuela en otro tipo de representación visual: lo conseguirá en el mapa Michelin, en esa totalidad del territorio rural habitado por su abuela, reflexión que de manera indirecta nos hace además volver a la ausencia de la figura humana en la obra de Martin, donde una parte (la abuela) será reconocida en el todo (el territorio).

La fotografía autentifica, Barthes reconoce que "su madre ha sido" en la fotografía del invernadero, al observar dicha imagen se encuentra con el momento en que ella posó frente al ojo de la cámara. Pero hay en el caso de Martin un desplazamiento en donde la fotografía reconoce y encuentra a su abuela registrando el "acá esto ha sido"; la fotografía del mapa objetiviza un espacio geográfico (el territorio donde ese ser querido vivió), lo que nos pone en relieve que claramente que: "no existe una sola manera de acercarnos a la cosa recordada (...) numerosos puntos de vista o estímulos conducen hacia ella." (BERGER, 1998, p. 84).

\section{Conclusiones}

- Hemos revisado como Houellebecq ha urdido en la novela una suerte de juegos de espejos entre representaciones, donde hemos problematizado principalmente la que se da entre el mapa y la fotografía.

- Existe en dichas representaciones, en ese volver a presentar, una acumulación de distintas capas que van mediando la aprehensión humana del mundo "real": desde la apropiación humana del paisaje, la vehiculización de éste por el territorio, su posterior representación en el mapa y en el caso específico de la novela, el mapa que es fotografiado.

- La importancia del lugar de constitución de la mirada fotográfica, ya que ésta articula y ancla fuertemente el sentido de la imagen.

\section{BIBLIOGRAFÍA}

AUGÉ, Marc. Los no lugares: espacios del anonimato. Barcelona: Gedisa, 2000

BARTHES, Roland. La cámara lúcida. Buenos Aires: Paidós, 2008.

BAUDRILLARD, Jean. Cultura y simulacro. Barcelona: Kairós, 1978.

BENJAMIN, Walter. Pequeña historia de la fotografía. In: BENJAMIN, Walter. Discursos interrumpidos I. Buenos Aires: Taurus, 1989.

BENJAMIN, Walter. La obra de arte en la era de la reproductibilidad técnica. México: Itaca, 2003. BERGER, John. Mirar. Buenos Aires: Ediciones de la Flor, 1998.

BORGES, Jorge Luis. Del rigor en la ciencia. In: BORGES, Jorge Luis. Obras completas: 1923-1972. Buenos Aires: Emecé Editores, 1974

CATALÁ DOMÈNECH, Josep M. La rebelión de la mirada: introducción a una fenomenología de la interfaz. Formats, Barcelona, n. 3, p. 51-44, 2001. Disponível em: https://www.raco.cat/ index.php/Formats/article/view/256098. Acesso em: 15 mayo 2015.

DEBORD, Guy. La sociedad del espectáculo. Buenos Aires: La Marca, 2007. 
GÓMEZ PIÑEIRO, Javier. Las técnicas tradicionales del análisis geográfico. Lurr@lde, [s. l.], n. 17, 341-356, 1994 Disponível em: http://www.ingeba.org/lurralde/lurranet/lur17/17gomez/17gomez. htm. Acesso em: 15 mayo 2015

HOUELLEBECQ Michel. El mapa y el territorio. Barcelona: Editorial Anagrama, 2011.

KORZYBSKI, Alfred. On structure. In: KORZYBSKI, Alfred. Science and sanity: an introduction to non-Aristotelian systems and general semantics. 5. ed. Englewood: Institute of General Semantics, 1994. chap. IV, p. 55-65.

RAMA, Ángel. La ciudad letrada. Montevideo: Arca Editorial, 1998.

SONTAG, Susan. Sobre la fotografía. México: Alfaguara, 2006 